\title{
The history of off-pump coronary bypass (opcab)
}

Keywords: coronary artery, bypass graft, surgeons, aortogram, thoracic artery

Abbreviations: OPCAB, off-pump coronary artery bypass; BITA, bilateral internal thoracic artery; LV, left ventricle; LITA, left internal thoracic artery; LAD, left anterior descending; CABG, coronary artery bypass graft; CX, circumflex system; RITA, right internal thoracic artery; $\mathrm{CAD}$, coronary artery disease; TIA, transient ischemic attack; MIDCAB, minimally invasive direct coronary artery bypass; MINI OPCABG, off-pump coronary artery bypass interventional cardiology; US, ultrasound

\section{Short communication}

Despite Alexis Carrel early description of experimental coronary artery bypass graft, ${ }^{1}$ surgeons were unable to translate these techniques successfully to humans due to a lack of technology and tools to operate on the unsupported beating heart. In 1952, Demikhov described the use of the LITA to directly graft the left anterior descending in dogs, with graft patency confirmed for up to $2-$ years. ${ }^{2}$ Similar early success with the use of the ITA was reported by Canadian surgeon Gordon Murray. ${ }^{3}$ Willian Longmire was apparently the first surgeon in performing an Off-pump coronary artery bypass operation. He said they performed a couple of the earliest internal mammary coronary anastomosis when they were forced into it when the coronary artery they were endarterectomizing disintegrated and in the desperation they anastomoses the left internal mammary artery to the distal end of the right coronary artery. ${ }^{4}$

In 1960, Robert Hans Goetz clearly performed the first successful bypass operation grafting the right internal mammary to the right coronary artery. His medicals and surgical colleagues vehemently criticized him hence he never performed a CABG again in this Hospital. ${ }^{5}$ The first venous coronary bypass graft ever performed was in $4^{\text {th }}$ April 1962 by Sabiston. The patient had an occlusion of the right coronary artery and a saphenous vein was intentionally taken from the leg and anastomosed between the ascending aorta and the right coronary artery. Their cardiologists rapidly spread the news of this procedure but unfortunately the patient later had a stroke and $\operatorname{died}^{6}$ on $25^{\text {th }}$ February 1964, the same year that Spencer performed the first LITA anastomosis to the LAD in the US with extracorporeal circulation. ${ }^{7}$ Kolesov performed the first successful CABG using the suture technique with specially designed magnifying glasses and scissors; he grafted the LITA to the left circumflex artery in a patient, who remained free of angina after 3-years of follow-up. ${ }^{8}$

Garrett, Dennis and DeBakey also performed a successful unplanned CABG on November $23^{\text {rd }} 1964$, and reported 7 years after. ${ }^{9}$ Up until the late 1950s, the main obstacle to the evolution of CABG surgery was an inability to image the coronary tree and link symptoms with specific patterns of obstructive coronary disease. On October $30^{\text {th }}$ 1959, Mason Sones of the Cleveland Clinic inadvertently performed the world's first coronary angiogram. While undertaking an aortogram on a 24-year-old man with rheumatic heart disease, he accidently injected contrast into the right coronary artery. ${ }^{10}$ This led to the birth of coronary angiography and intense interest in coronary imaging, which generated a greater understanding of coronary anatomy.
Volume I Issue $3-2017$

\author{
Federico Benetti, Natalia Scialacomo \\ President Benetti Foundation
}

Correspondence: Federico Benetti, President Benetti Foundation, Alem 1846, Rosario, Santa Fe, Zip 2000, Argentina, Email federicobenetti@hotmail.com

Received:September II, 2017 | Published: November 22, 2017

The ability to image the coronary arteries allowed Sones and his colleagues, including Donald Effler and Rene Favaloro, to describe two distinct patterns of CAD, namely proximal and diffuse obstructive disease. The Cleveland group initially advocated alternative management strategies for these two patterns, recommending localized patch grafting for proximal disease and the Vineberg procedure for diffuse disease interestingly. In 1966, Favaloro reported to have performed bilateral internal thoracic artery (BITA) grafting using the indirect Vinberg technique where the RITA was placed in the left ventricle (LV) parallel to the LAD and the LITA in the lateral wall of the LV between the branches of the circumflex and right coronary arteries with good clinical result.

Though the Cleveland Clinic reported reasonable results with the indirect Vineberg technique, they had a higher mortality rate (11 of 14 patients) with the proximal patch graft technique. The high mortality associated with direct coronary patching led to the use of the saphenous vein. Initially, in May 1967, the saphenous vein was used in an endto-end fashion to replace an occluded segment of the right coronary artery. Favaloro reported the use of the saphenous vein graft in direct coronary surgery in 180 patients ${ }^{11}$ and Johnson in 301 patients more or less at the same time..$^{12}$ This was an important landmark in the birth of modern coronary surgery. Although the origins of coronary surgery began with the arterial graft, the saphenous vein, with its technical ease of harvest, its robust handling characteristics and its versatility as an aorto-coronary graft, simplified the conduct of the operation and allowed for widespread reproducibility. In 1975 Ankeney presented Coronary vein graft without cardiopulmonary bypass in a surgical motion picture. ${ }^{13}$ Also Trapp and Bisarya, in 1975 presented a work using coronary perfusion off pump. ${ }^{14}$

Trying to decrease the risks of the CABG and costs, in 1978 we repopularized the Off Pump Coronary Artery Bypass Graft (OPCAB) and expanded the technique, addressing lesions of the circumflex system (CX) and applying it to diverse clinical scenarios. ${ }^{15,16}$ Several surgical approaches were tested, such as full sternotomy, no spreading sternotomy including left, anterolateral, posterolateral and right anterolateral thoracotomies, as well as partial sternotomy. ${ }^{17}$

The video-assisted techniques in the nineties allowed us, for the first time, to dissect the left internal thoracic artery (LITA) without opening the pleura cavity. Benetti anastomoses the LITA to the left anterior descending (LAD) through a small left anterior thoracotomy for the first time. We did many technological developments that allowed us to train surgeons in 45 countries of the world in Off Pump Coronary Surgery. ${ }^{18-20}$ 
Although the MIDCAB is a good operation full or partial lower sternotomy, it carries little morbidity and allows excellent access for LAD and right coronary artery anastomoses. With further experience, the circumflex marginal vessels can be approached. ${ }^{21}$

In 1997, Benetti performed for the first time an ambulatory coronary bypass through a xiphoid lower sternotomy incision (MINI OPCAB) using 3D technology to assist in the operation. ${ }^{22,23}$ In 1998, Didier Loulmet performed the first endoscopic bypass using robotic. ${ }^{24}$ We used the right mammary as inflow from many years in sternotomy off pump when the patient had a porcelain aorta, and we expanded this technique for the MINI OPCAB operation in multiple vessels. ${ }^{25}$

With these and other, contributions regarding to different conduits adapted to the OPCAB, this surgery is today established worldwide. The future requires a bypass operation more minimally invasive, easy to reproduce and with possibilities to be done in the entire world.

\section{Acknowledgements}

The Acknowledgement is for all the surgeons that make the $\mathrm{OPCAB}$ surgery possible and for the Benetti Foundation for the economical support.

\section{Conflict of interest}

The author declares all my inventions and patents related with the $\mathrm{OPCAB}$ and MIDCAB operations were assigned to CTS (Cardiothoracic Surgery) and I don perceived any royalty.

\section{References}

1. Carrel A. VIII On the Experimental Surgery of the Thoracic Aorta and Heart. Ann Surg. 1910;52(1):83-95.

2. Demikhov V. Experimental transplantation of vital organs. Authorized translation from the Russian by Basil Haigh. USA: Consultant's Bureau; 1910. 24 p.

3. Murray G, Porcheron R, Hilario J, et al. Anastomosis of systemic artery to the coronary. Can Med Assoc J. 1954;71(6):594-597.

4. Longmire WP, Cannon JA, Kattus AA. Direct-vision coronary endarterectomy for angina pectoris. $N$ Engl J Med. 1958;259(21):993999.

5. Goetz RH, Rohman M, Haller JD, et al. Internal mammary-coronary artery anastomosis. A nonsuture method employing tantalum rings. $J$ Thorac Cardiovasc Surg. 1961;41:378-386.

6. Sabiston DC. The coronary circulation. The John Hopkins.

7. Spencer FC, Yong NK, Prachuabmoh K. Internal mammary-coronary artery anastomoses performed during cardiopulmonary bypass. $J$ Cardiovasc Surg (Torino). 1964;5:292-297.
8. Kolesov VI, Potashov LV. Surgery of coronary arteries. Eksp Khir Anesteziol. 1965;10:3-8.

9. H Amer Chaikhouni. Heart Views. 2010;11(1):31-37.

10. Sones FM Jr, Shirey Ek. Cine coronary arteriography. Mod Concepts Cardiovasc Dis. 1962;31:735-738.

11. Favaloro RG. Saphenous vein graft in the surgical treatment of coronary artery disease. Operative technique. J Thorac Cardiovasc Surg. 1969;58(2):178-185.

12. Johnson WD, Flemma RJ, Lepley D, et al. Extended treatment of severe coronary artery disease: a total surgical approach. Ann Surg. $1969 ; 170(3): 460-470$.

13. Ankeney JL. Coronary vein graft without cardiopulmonary bypass: a surgical motion picture. Ann Thorac Surg. 1975;1:19.

14. Trapp WG, Bisarya R. Placement of coronary artery bypass graft without pump oxygenator. Ann Thorac Surg. 1975;19(1):1-9.

15. Benetti FJ. Direct coronary surgery with saphenous vein bypass without either bypass or cardiac arrest. J Cardiovasc Surg (Torino). $1985 ; 26(3): 217-222$.

16. Buffolo E, Andrade JC, Succi J, et al. Direct Myocardial Revascularization without Cardiopulmonary Bypass. Thorac Cardiovasc Surg. 1985;33(1):26-29.

17. Benetti FJ, Naselli G, Wood M, et al. Direct Myocardial revascularization without extracorporeal circulation Experience in 700 patients. Chest. 1991;100(2):312-316.

18. Benetti FJ. Uso de la Toracoscopia en cirugía coronaria para la disección de la mamaria izquierda. La Prensa Medica Argentina. 1994;9:81-87.

19. Benetti FJ, Ballester C. Use of the Thoracoscopy and a minimal Thoracotomy in mammary coronary bypass to left descending artery, without extracorporeal circulation Experience in 2 cases. $J$ Cardiovasc Surg. 1995;36(2):159-161.

20. Benetti FJ. Method for coronary artery bypass. US Patent 5. 888:247.

21. Westaby S, Benetti FJ. Less invasive coronary surgery: consensus from the Oxford Meeting. Ann Thorac Surg. 1996;62:924-931.

22. Benetti FJ. Minimally Invasive coronary surgery (the xiphoid approach). Eur J Cardiothoracic Surg. 1999;16(Suppl 2):S10-S11.

23. Benetti FJ. Xyphoid access for cardiac surgical procedures. US Patent. 6199556 B1

24. Loulmet D, Carpentier A, d'Attellis N, et al. Endoscopic coronary artery bypass grafting with the aid of robotic assisted instruments. $J$ Thorac Cardiovasc Surg. 1999;118(1):4-10.

25. Benetti FJ, Prapas S, Angeletti E, et al. Xiphoid-Lower-sternotomy approach for multivessel revascularization of the left internal mammary to the left anterior descending Artery and the Right internal mammary as inflow to the others vessels. Heart Surg Forum. 2010;13(1):E36-E39. 